\begin{tabular}{|c|c|} 
European Association for the & $\begin{array}{c}\text { International Conference on Renewable Energies and Power Quality } \\
\text { (ICREPQ'12) }\end{array}$ \\
and Power Quality (EA4EPQ) & $\begin{array}{c}\text { Santiago de Compostela (Spain), 28th to 30th March, 2012 } \\
\end{array}$
\end{tabular}

\title{
Decision Support in the Investment Analysis on Efficient and Sustainable Electrical Equipment
}

\author{
J.A. Lobão ${ }^{1}$, T. Devezas ${ }^{2}$ and J.P.S. Catalão ${ }^{2}$ \\ ${ }^{1}$ Polytechnic Institute of Guarda \\ Av. Dr. Francisco Sá Carneiro 50, 6300-559 Guarda (Portugal) \\ Phone: +351271220 111, Fax: +351271220690 \\ e-mail: jlobao@ipg.pt \\ ${ }^{2}$ University of Beira Interior and CAST \\ R. Fonte do Lameiro, 6200-001 Covilhã (Portugal) \\ Phone: +351 275329 914, Fax: +351275 329972 \\ e-mail: tessalen@ubi.pt; catalao@ubi.pt
}

\begin{abstract}
Considering the current global economic situation and the rising energy costs, all contributions to the reduction in energy consumption will be relevant. In electrical installations, energy consumption can be reduced by reducing losses in the conductors, associated with the efficiency of equipments, allowing a better use of the installed power, which can be an important issue when using renewable energies. The losses in the conductors are proportional to the square of the resistance and current. These must be analysed in conjunction with all loads that contribute to the current in the sections of the installation. When replacing equipment in distribution boxes output by more efficient ones, the current decreases in sections covered with the most significant power loss due to proportionality with the square of the current. This decrease, often forgotten, is recorded in this work and included in the investment analysis on efficiency and sustainable electrical equipment. This analysis, combined with the features and operating parameters of electrical installation, accounts for all the gains that can make a difference in the choice of efficient equipment.
\end{abstract}

\section{Key words}

Electrical equipment, decision support, sustainable energy, efficiency, losses.

\section{Introduction}

This study presents a new software application under development that compares and chooses the best investment in the acquisition and installation of electrical equipment. The equipment choice focuses on the following factors: cost, power consumption, reduction of losses in the conductors, useful life and interest rate. The losses in the conductors will be analysed based on the current which passes throughout the electrical installation. It is also possible to determine the $\mathrm{CO}_{2}$ emissions reduction corresponding to the power consumption reduction.
This study will be based in a new way of thinking: from minimal investment cost to minimal lifecycle cost [1].

\section{Development}

\section{A. Identification of the Parameters}

Physical parameters:

- $\quad$ Distribution boxes (Q);

The distribution boxes are numbered from number 1 (initial distribution boxes) to the total number of distribution boxes for the installation.

- Connections between distribution boxes;

The connection of these distribution boxes is saved in a matrix that identifies the connection courses. The number contained in the matrix $[\mathrm{k}, \mathrm{i}]$ indicates the number of the respective output.

Figure 1 shows a connection matrix.

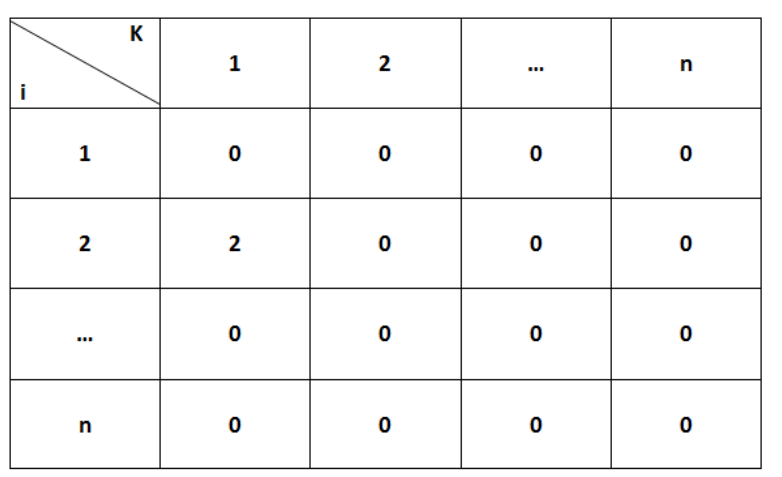

Fig.1. Connection matrix.

$\mathrm{k}$ : Distribution boxes it provides energy i: Distribution boxes which receives energy $[\mathrm{k}, \mathrm{i}]$ : Output in distribution boxes $\mathrm{k}$ 
For example:

Distribution boxes (k) 1 provides power to distribution boxes (i) 2 , the second output.

- Length of output conductors in distribution boxes;

- Section of outputs conductors in distribution boxes; From the length and section, is determined the resistance of the conductors for all outputs.

$$
\begin{aligned}
& R=\rho \frac{l}{s} \\
& \rho: \text { Resistivity } \\
& l: \text { Length } \\
& s: \text { Section }
\end{aligned}
$$

\begin{tabular}{|c|c|c|c|c|}
\hline 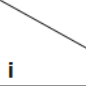 & 1 & 2 & $\ldots$ & $\mathrm{n}$ \\
\hline 1 & 0.168 & 0,281 & 0 & 0 \\
\hline 2 & 0.315 & 0,525 & 0 & 0 \\
\hline ... & 0 & 0 & 0 & 0 \\
\hline $\mathrm{n}$ & 0 & 0 & 0 & 0 \\
\hline
\end{tabular}

The values are saved in a resistances matrix, shown in Figure 2 .

Fig. 2. Resistances matrix
k: Distribution boxes
i: Outputs
$[\mathrm{k}, \mathrm{i}]$ :value of resistances
For example:
The outputs resistances (i) 2 distribution boxes
(k) 1 is $0.315 \Omega$.

Load parameters:

- Power of the loads connected to the electrical installation;

- Efficiency of the loads;

- Power factor of the loads;

- Daily load diagram (Figure 3);

The load diagram is analyzed within $24 \mathrm{~h}$ of the day, in intervals.

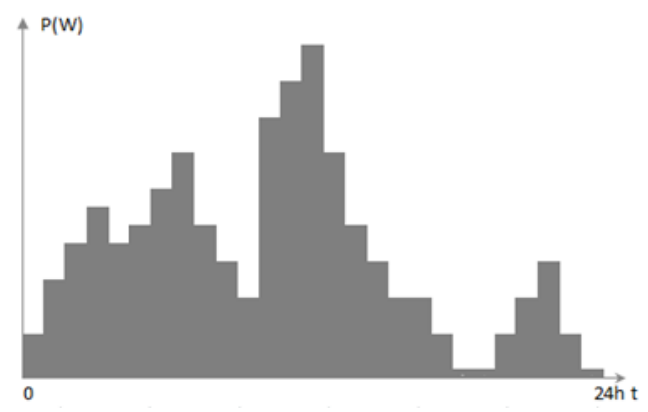

Fig. 3. Daily load diagram.

- Daily load diagram of the equipment for economic analysis.
Operating parameters:

- Operating time of the electrical installation;

- Monthly operating days (d);

- Months of annual operation (m);

- Cost of electricity (€)

The price of electricity is variable. The software allows the user to choose the tariff.

\section{B. Installation Characteristics}

Figure 4 shows a typical installation with the respective parameters.

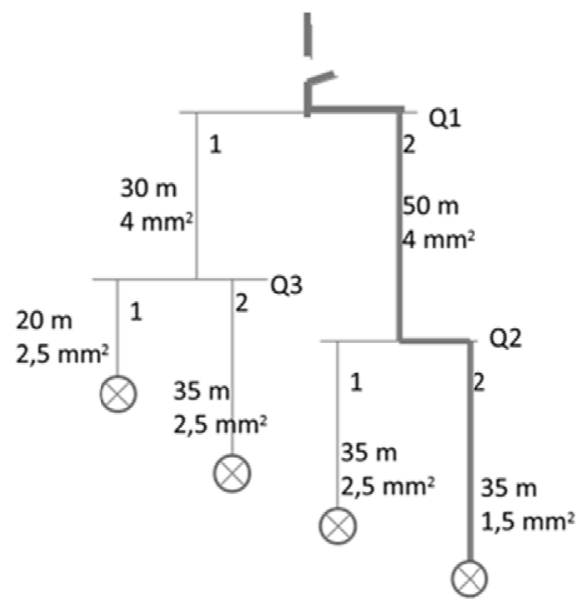

Fig. 4. Scheme of an installation.

\section{Calculations}

After the input of the parameters and load diagrams, the following calculations are made:

- Determination of the load diagram associated to the output distribution boxes (Figures 5-7), adding the corresponding load diagrams [2]. Example: the output "2" in "Q1" is the sum of outputs diagrams in "Q2".

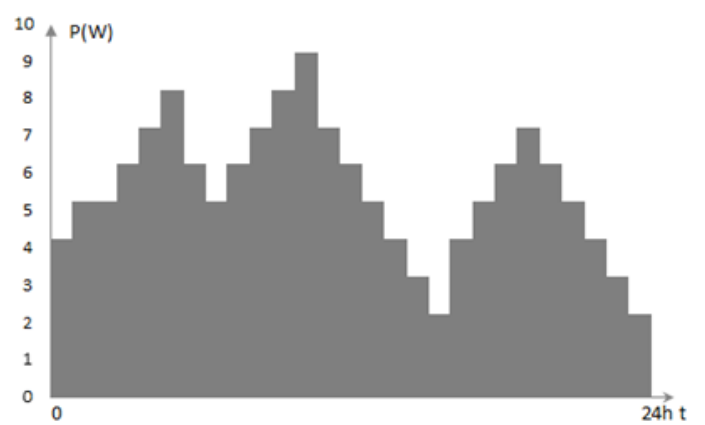

Fig.5. Load diagram $(2,1)$ : output diagram 1 of Q2.

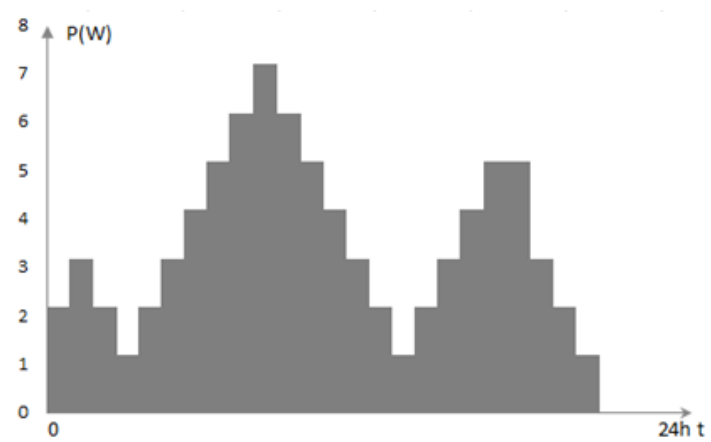

Fig.6. Load diagram $(2,2)$ : output diagram 2 of Q2. 


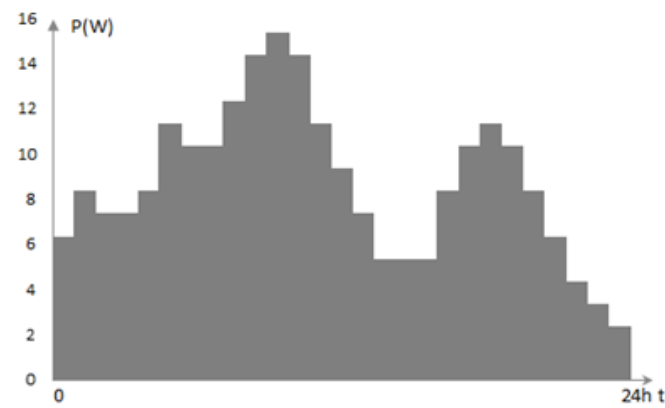

Fig.7. Load diagram $(1,2)$ : output diagram 2 of Q1.

- The currents in all conductors of the electrical installation due to:

-Initial load diagram $\left(\mathrm{I}_{1}\right)$

-Load diagram of the equipment $\left(\mathrm{I}_{2}\right)$.

- Difference in cable losses $(\Delta \mathrm{P})$ in the conductors affected by the changed equipment (identified in bold in Fig.4), given by:

$$
\Delta P=R\left(I_{1}\right)^{2}-R\left(I_{2}\right)^{2}
$$

(In all ranges of the load diagram)

- Profits from the variation of cable losses (G1) given by:

$$
(G 1)=\Delta P * d * m * €
$$

(In all ranges of the load diagram)

- Profits from the variation of power equipment (G2) given by:

$$
(G 2)=(P 1-P 2) * d * m * €
$$

(In all ranges of the load diagram)

- Total profits, given by:

$$
R=(G 1)+(G 2)
$$

\section{Economic Evaluation}

In this work, the VAL (net present value) is used, which is computed from the sum of the annual cash-flows for a given annual interest rate [3]-[4].

The interest rate is indicated by the investor according to the desired profitability.

$V A L=\sum_{k=0}^{n} \frac{R_{k}-D_{k}-I_{k}}{(1+a)^{k}}+\frac{V}{(1+a)^{n}}$

with:

$R$ - Net profit

$D$ - Operation cost

$I$ - New investment

$n-$ Years of useful life

$V$ - Residual value for the old equipment

$a$ - Annual interest rate

\section{Results}

Figure 8 shows a typical installation with the respective parameters, used as a likely example.

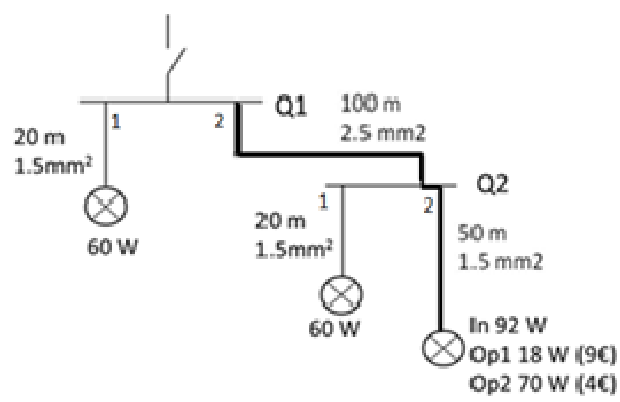

Fig. 8. Scheme of an installation.

The load diagrams are shown in Figures 9 to 12 . Figure 13 presents the preliminary results of the new software application to the scheme of Figure 8 . The results compare an initial situation of a normal incandescent lamp of $92 \mathrm{~W}$, with a fluorescent compact lamp of $18 \mathrm{~W}$ and another halogen one of $70 \mathrm{~W}$.

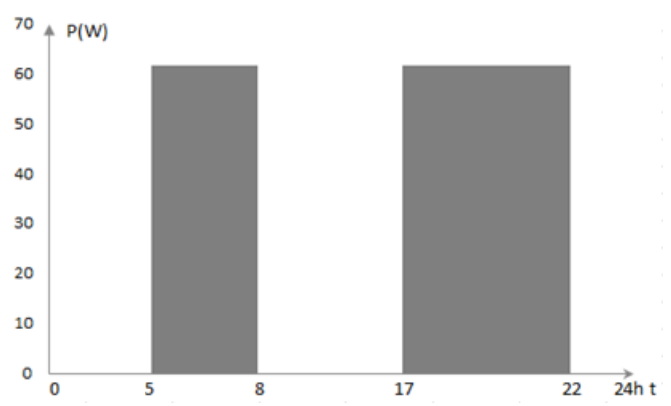

Fig.9. Load diagram $(1,1)$ and $(2,1)$ : output 1 of Q1 and output 1 of Q2.

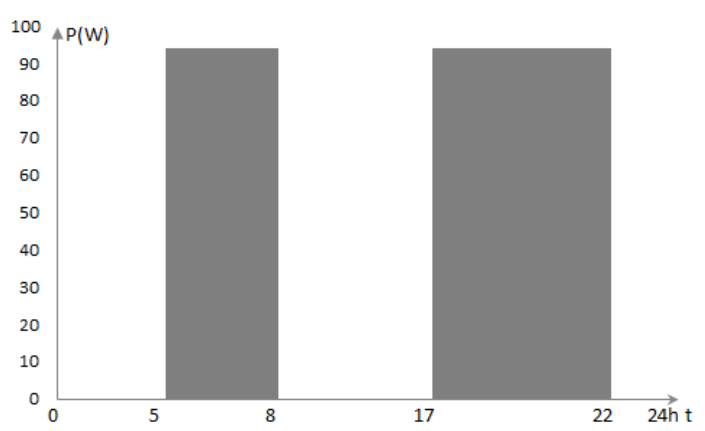

Fig.10. Load diagram (2,2): Output 2 of Q2 (Op1).

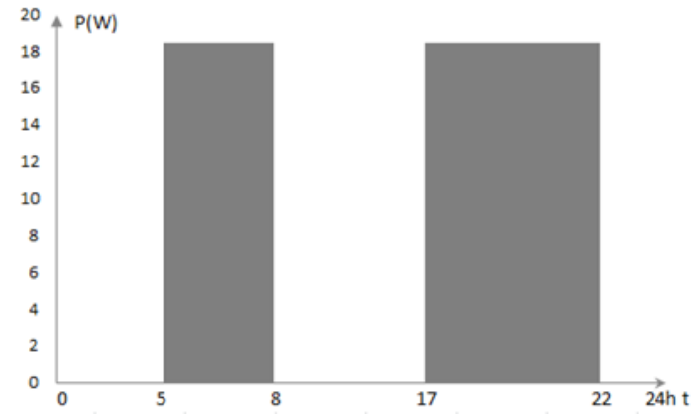

Fig.11. Load diagram $(2,2)$ : output 2 of Q2 (Op2). 


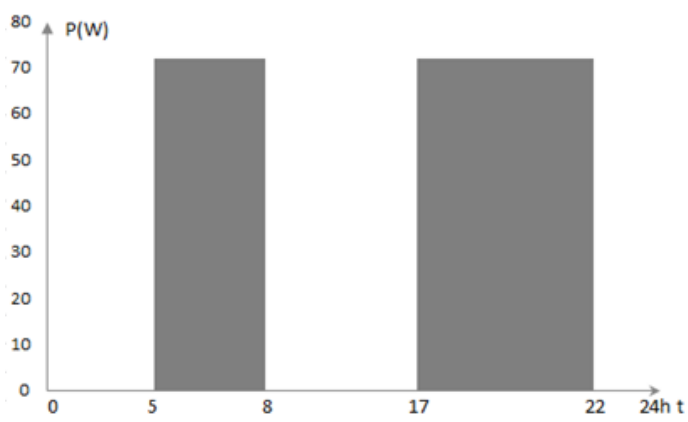

Fig.12. Load diagram (2,2): output 2 of Q2 (Op3).

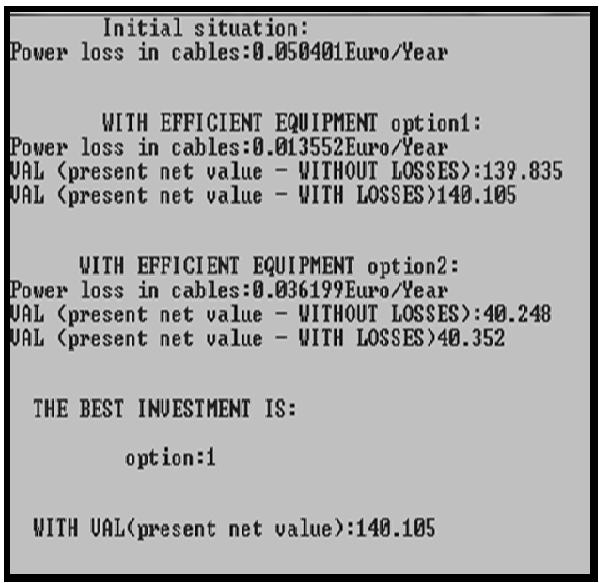

Fig. 13. Results of the new software application.

\section{Conclusion}

The application under development is intended to demonstrate that the losses caused by the electrical equipment in all conductors influences their choice. These losses in electrical installations, although small, are not null and can make a considerable difference in the economic evaluation, supporting the investment decision. The results presented confirm that the VAL is superior when the losses are included, thus validating our study. The sum of all those small contributions shall provide great help in reducing overall energy consumption.

\section{References}

[1] F. Nuño, "Energy saving potential of cable renovation and economic cable sizing", in: ICREPQ'11, Gran Canaria, Spain, April 2011.

[2] J.A. Lobão, "Correction of power factor", Master Thesis, University of Coimbra, Portugal, December 1995 (in Portuguese).

[3] A.H.M. Santos, E.C. Bortoni, "Analysis of three-phase induction motors under conditions of technical and economical uncertainty aiming energy conservation", Federal Engineering School of Itajubá, Itajubá, Brazil.

[4] H. Barros, "Análise de projetos de investimentos ", Ed Silabo, Lisbon, 2008 (in Portuguese). 